\title{
Bacterial composition and inferring function profiles in the biofloc system rearing Litopenaeus vannamei postlarvae at a low salinity
}

\author{
Hai-Hong Huang ${ }^{1 *}$, Chao-Yun Li $^{2 \dagger}$, Yan-Ju Lei ${ }^{1,3}$, Wei-Qi Kuang ${ }^{1,4}$, Wan-Sheng Zou ${ }^{1,5}$, Pin-Hong \\ Yang ${ }^{1,6}$
}

${ }^{1}$ College of Life and Environmental Sciences, Hunan University of Arts and Science, Changde Hunan, China

${ }^{2}$ Shandong Vocational Animal Science and Veterinary College, Weifang 261061, China

${ }^{3}$ Collaborative Innovation Center for Efficient and Health Production of Fisheries in Hunan Province, Changde Hunan, China

${ }^{4}$ Hunan Engineering Research Center of Aquatic Organism Resources and Environmental Ecology, Changde Hunan, China

${ }^{5}$ Academician workstation

(Fisheries) of Hunan Province, Changde Hunan, China

${ }^{6}$ Hunan Provincial Key Laboratory for Molecular Immunity Technology of Aquatic Animal Diseases, Changde Hunan, China

Correspondence

Hai-Hong Huang, Hunan University of Arts and Science. Changde, 415000, China. Email: shinkanh@nwsuaf.edu.cn

Funding information

Scientific research program of the Education Department of Hunan province, China, Grant/Award Number: 18B394

\begin{abstract}
This study aimed to investigate the bacterial composition and inferring function profiles in the biofloc system rearing Litopenaeus vannamei postlarvae (PL) at a low salinity condition. PL ( stage 15$)$ were stocked in four parallel tanks filled in water with a salinity of $5.0 \%$ at a density of 4000 individuals per $\mathrm{m}^{3}$ for a 28-days culture experiment, during which glucose was added as carbon source with a $C: N$ of $20: 1$. At the end of experiment, water was sampled from each tank and pooled to extract microbial DNA for high-throughput sequencing of V3-V4 region of $16 \mathrm{~S}$ rRNA gene. Results showed that the bacterial community at $28 \mathrm{~d}$ was dominated by phyla of Proteobacteria (45.8\%), Bacteroidetes (21.1\%), Planctomycetes (13.5\%), Chlamydiae (10.3\%) and Firmicutes $(6.8 \%)$. A proportion of $81 \%$ inferring KEGG functions of this bacterial community associated with metabolism. Among functions relating to nitrogen metabolism, $48.5 \%$ were involved in the conversion of ammonia to glutamate, but the proportion of those involved in transformation among ammonia, nitrite and nitrate was $18.0 \%$ in total, inferring higher protein-synthesis but lower inorganic nitrogen-transformation capacities of the bacterial community. At the same time $(28 \mathrm{~d})$, high levels of total nitrogen $\left(231.3 \pm 6.0 \mathrm{mg} \mathrm{L}^{-1}\right)$ and biofloc $\left(127.0 \pm 63.0 \mathrm{~mL} \mathrm{~L}^{-1}\right)$, but low concentrations of ammonia $\left(0.04 \pm 0.01 \mathrm{mg} \mathrm{L}^{-1}\right)$, nitrite $\left(0.2 \pm 0.1 \mathrm{mg} \mathrm{L}^{-1}\right)$ and nitrate $\left(12.9 \pm 2.5 \mathrm{mg} \mathrm{L}^{-1}\right)$ were observed. The results supply a novel insight for understanding the function of bacterial community in the biofloc system nursing $L$. vannamei PL at a low salinity.
\end{abstract}

\section{KEYWORDS}

Litopenaeus vannamei, Biofloc technology, High-throughput sequencing, Inferring functions, Nitrogen metabolism

\section{INTRODUCTION}

Litopenaeus vannamei is the most important cultured crustaceans species in the world, whose culture production accounted for $52.9 \%$ of the total crustaceans production in 2018 (FAO, 2020). During culture of L. vannamei, after larvae period and before grow-out period, postlarvae (PL) are sequentially nursed for an intermediate period called the prenursery phase
(Mishra, Samocha, Patnaik, Speed, Gandy, \& Ali, 2008; Rezende Schleder, Silva, Henriques, Lorenzo, Seiffert, . . . \& Vieira, 2018), to deliver large $\mathrm{PL}$ that are resistant to environmental conditions to increase the survival and growth performance. However, in the conventional prenursery system, due to intensively high stocking density $\left(\sim 60 \mathrm{PL} \mathrm{L}^{-1}\right)$, controlling of toxic ammonia and nitrite is a big problem, as well as the biosecurity followed by

\footnotetext{
* Corresponding authors.E-mail address: shinkanh@nwsuaf.edu.cn, shinkanh@huas.edu.cn.

$\dagger$ Co-first author.
} 
operations such as water exchange for management of those nitrogen compounds (Samocha, 2010). Recently, biofloc technology (BFT) has been tried to be used to nurse $L$. vannamei PL (Khanjani, Sajjadi, Alizadeh, \& Sourinejad, 2017; Rezende, Schleder, Silva, Henriques, Lorenzo, Seiffert, . . . \& Vieira, 2018; Schveitzer, Lorenzo, Felipe, Pereira, Mourino, Seiffert, \& Andreatta, 2017), due to the advantages of this technology on nitrogen assimilation in situ and pathogen control under minimal or zero water exchange conditions (Avnimelech, 2015; Huang, 2020). Besides, biofloc is also rich in nutrients, immunostimulants and bioactive compounds, such as essential amino acids (Li, Liu, Li, Deng, Abubakar, Lan, ..., \& Liu, 2018), unsaturated fatty acids (Ray, Leffler, \& Browdy, 2019), lipopolysaccharide (LPS) and carotenoids ( Ju, Ian, Lytha, Warren, Wenhaocedric, \& Floyd, 2008; Vargas-Albores, Martínez-Córdova, Gollas-Galván, Garibay-Valdez, Emerenciano, Lago-Leston, . . . \& Martínez-Porchas, 2019), contributing to growth-improvement, immuneenhancement and probiotic effects for shrimp (Panigrahi, Sundaram, Saranya, Kumar, Dayal, Saraswathy, ... \& Gopal, 2019).

Biofloc is an aggregate of bacteria, protozoan, feces and organic detritus (Avnimelech, 2015; Schryver, Crab, Defoirdt, Boon, \& Verstraete, 2008), among which the bacterial community is considered to play an of importance role for the advantages of biofloc mentioned above (Cardona, Gueguen, Magre, Lorgeoux, Piquemal, Pierrat, . . . \& Saulnier, 2016; Ju, Ian, Lytha, Warren, Wenhaocedric, \& Floyd, 2008). Previous studies show that the bacterial community in the marine water biofloc systems rearing $L$. vannamei is dominated by Proteobacteria, Bacteroidetes, Planctomycetes and Firmicutes (HuertaRabago, Martinez-Porchas, Miranda-Baeza, Nieves-Soto, Rivas-Vega, \& MartinezCordova, 2019; Martínez-Córdova, Francisco, Estefanía, Ortíz-Estrada, Porchas-Cornejo, Asunción, \& Marcel, 2018; Vargas-Albores, Martínez-Córdova, Gollas-Galván, GaribayValdez, Emerenciano, Lago-Leston, . . . \& Martínez-Porchas, 2019; Xu, Xu, Huang, Hu, $\mathrm{Xu}, \mathrm{Su}$, . . . \& Cao, 2019). Those phyla are important to the maintenance of a good water quality for biofloc system because many species belonging to them use organic matter and nitrogen compounds for growth, such as Thiotrichaceae, Rhodobacteraceae and Saprospiraceae (Cardona, Gueguen, Magre, Lorgeoux, Piquemal, Pierrat, . . . \& Saulnier, 2016). Additionally, the inferring functions of bacterial community in biofloc system, including nitrogen metabolism, biosynthesis of nutrients, immunostimulants and bioactive compounds, indicate associations of bacterial community with shrimp growth and water quality (Hargreaves, 2013; Ju, Ian, Lytha, Warren, Wenhaocedric, \& Floyd, 2008; Vargas-Albores, Martínez-Córdova, GollasGalván, Garibay-Valdez, Emerenciano, LagoLeston, . . . \& Martínez-Porchas, 2019). From this point of view, studies on bacterial composition and its inferring function profiles would supply deep insights on understanding the role of bacterial community in the biofloc system.

L. vannamei is an euryhaline species which could be cultured at low salinity conditions less than $1.0 \%$, which is a trend that will continue to grow globally (Roy, Davis, Saoud, Boyd, Pine, \& Boyd, 2010). Osmoregulation capability of L. vannamei develops gradually in the postlarvae stages and can easily be acclimated to salinities as low as $0.5 \%$ by PL12 (Van Wyk, Davishodgkins, Laramore, Main, Mountain, \& Scarpa, 1999), indicating that PL after stage 12 could be reared at a low salinity condition for a prenursery phase. And recently, in some studies, biofloc technology had been used for prenursery of $L$. vannamei PL under low salinity conditions (816\%o) (Esparza-Leal, Amaral Xavier, \& Wasielesky, 2016; Luo, Liu, Shan, \& Tan, 2019). However, there is little information about bacterial community and its inferring functions in the low-salinity biofloc system until now.

This study aimed to investigate the bacterial composition and inferring function profiles in a biofloc system rearing L. vannamei PL at a salinity of $5.0 \%$, to deeply understand the function of bacterial community in the biofloc system.

\section{MATERIAL AND METHODS}

\subsection{Ethic statement}

The experiments were carried out at a local farm of Bifuteng eco-agriculture development Co., Ltd. (BEAD Co., Lat. 28 $53^{\prime} 57.88^{\prime \prime} \mathrm{N}$, Long. 111 38'3.08" E) and Hunan University of Arts and Science (HUAS, Lat. 29³'0.12" N, Long. $111^{\circ} 40^{\prime} 11.43^{\prime \prime} \mathrm{E}$ ), both of which locate in Changde, China, under principles in good laboratory animal care, according to the national standard of China (GB/T 35892-2018), 'Laboratory animal-Guideline for ethical 
review of animal welfare'. The manuscript does not require ethical approval.

\subsection{Preparation of culture water}

Water with a salinity of $5.0 \%$ for culture experiment was prepared according to Ray and Lotz (2017), with some modifications. Briefly, artificial sea salt powder (Qianglong corporation, Tianjin, China), and food grade chemical reagents of $\mathrm{KCl}, \mathrm{MgCl}_{2}$ and $\mathrm{CaCl}_{2}$ were added to tap water to make a final salinity of 4.96\% ( $5.0 \%$ ), with $\mathrm{K}^{+}, \mathrm{Mg}^{2+}$ and $\mathrm{Ca}^{2+}$ concentrations of 292,934 and $318 \mathrm{mg} \mathrm{L}^{-1}$, respectively. Then, the water $\mathrm{pH}$ value was adjusted to near 8.0 by using food grade $\mathrm{NaHCO}_{3}$. After that, sterilization $\left(10.0 \mathrm{mg} \mathrm{L}^{-1}\right.$ chlorinedioxide) followed by neutralization (1.0 $\mathrm{mg} \mathrm{L}^{-1}$ ascorbic acid) were executed according to the processes of previous studies (Gaona, Almeida, Viau, Poersch, \& Wasielesky, 2017; Lara, Krummenauer, Abreu, Poersch, \& Wasielesky, 2017).

\subsection{Experimental design and operations}

Four indoor tanks (width $\times$ length $\times$ depth $=$ $2 \times 2.5 \times 1.3 \mathrm{~m})$ of BEAD Co., each of which fixed five porous tubes $(2.4$ meter in length) in the bottom connecting with a 750-w whirl charging aerator (HG-750S, Sensen Group Co., Ltd., Zhoushan, China), were filled with $5.0 \mathrm{~m}^{3}$ culture water prepared above. $L$. vannamei PL ( PL15, 2.5 $\pm 0.5 \mathrm{mg})$ which had been treated with a desalinating and acclimation procedure to adapt the experimental conditions (Luo, Liu, Shan, \& Tan, 2019; Van Wyk, Davishodgkins, Laramore, Main, Mountain, \& Scarpa, 1999), were kindly supplied from BEAD Co. and randomly assigned to the four experimental tanks with a stocking density of 4000 individuals per $\mathrm{m}^{3}$ for a 28-days culture. During the whole culture period, PL were fed with a commercial formulated shrimp diet (crude protein $40.0 \%$, crude lipid $5.0 \%$, crude fibber $5.0 \%$, crude ash $15.0 \%$, moisture $12.0 \%$, Alpha corporation, Jiangmen, Guangdong, China), with a frequency of four times equally a day $(6: 00,12: 00,18: 00,24: 00)$, at feeding rates of $25-35 \%$ and $20-25 \%$ corresponding to the average shrimp weight of $<0.1 \mathrm{~g}$ and $>0.1$ $\mathrm{g}$, respectively, basing on the estimated total biomass and operations of Van Wyk, Davishodgkins, Laramore, Main, Mountain, \& Scarpa (1999). Besides, glucose (food grade, carbohydrate content $90.0 \%$, Fufeng biotechnology Co., Ltd., Hohhot, Inner
Mongolia Autonomous, China) was added as exogenous carbon source, according to a carbon to an inputted nitrogen ratio (C:N) of 20:1 (Ebeling, Timmons, \& Bisogni, 2006) contained in feed and carbon source inputted each time. The inputted C:N was the C:N contained in the inputted materials (feed and carbon source). Briefly, $0.9 \mathrm{~g}$ carbohydrate or $0.36 \mathrm{~g}$ carbon ( $40 \%$ carbon in carbohydrate) is contained in $1.0 \mathrm{~g}$ glucose with a carbohydrate content of $90.0 \%$. Meanwhile, $0.4 \mathrm{~g}$ protein or $0.064 \mathrm{~g}$ nitrogen ( $16 \%$ nitrogen in protein) is contained in $1.0 \mathrm{~g}$ formulated feed due to the crude protein content of $40.0 \%$ (Avnimelech, 1999; Ebeling, Timmons, \& Bisogni, 2006). Meanwhile, about $0.384 \mathrm{~g}$ carbon is contained in $1.0 \mathrm{~g}$ feed according to the calculating method of Kumar, Anand, De, Deo, Ghoshal, Sundaray, . . . \& Lalitha (2017). Thus, $1.6 \mathrm{~g}$ glucose needed to be inputted when $1.0 \mathrm{~g}$ feed was fed to shrimp, according to the inputted carbon to nitrogen ratio $(\mathrm{C}: \mathrm{N})$ of $20: 1$ and the conception that $25 \%$ is theoretically converted as shrimp biomass and $75 \%$ would be lost to water body (Piedrahita, 2003). Throughout the whole experimental period, no water exchange was operated, but evaporating loss was complemented with dechlorinated tap water per week.

\subsection{Water sampling and high-throughput sequencing of $16 \mathrm{~S}$ rRNA gene}

At $28 \mathrm{~d}, 50 \mathrm{ml}$ water was collected from each tank and pooled as one sample according to the method by Martínez-Córdova, Francisco, Estefanía, Ortíz-Estrada, Porchas-Cornejo, Asunción, \& Marcel (2018); and $200 \mathrm{ml}$ sample was obtained in total. The water sample was filtered through a $0.22-\mu \mathrm{m}$ pore size membrane. After that, the membrane was collected to extract bacterial DNA genome with an E.Z.N.A ${ }^{\mathrm{TM}}$ Mag-Bind Soil DNA Kit (OMEGA Bio-Tek, Inc., GA, USA), according to the manufacturers' instructions. The genome was taken as template to amplify the V3-V4 region of $16 \mathrm{~S}$ rRNA gene with the universal primers, 341F: 5'CCTACGGGNGGCWGCAG-3' and 805R: 5'-GACTACHVGGGTATCTAATCC-3', in a 30- $\mu 1$ mixtures containing microbial DNA (10 $\mathrm{ng} / \mu \mathrm{l}) 2 \mu \mathrm{l}$, forward primer $(10 \mu \mathrm{M}) 1 \mu \mathrm{l}$, reverse primer $(10 \mu \mathrm{M}) 1 \mu \mathrm{l}$, and $2 \mathrm{X}$ KAPA HiFi Hot Start Ready Mix $15 \mu$ l (TaKaRa Bio Inc., Japan), via a two-stage PCR procedure with a thermal instrument (Applied Biosystems 9700, USA): 1 cycle of denaturing at $95^{\circ} \mathrm{C}$ for $3 \mathrm{~min}$, first 5 cycles of denaturing at $95^{\circ} \mathrm{C}$ for 
$30 \mathrm{~s}$, annealing at $45^{\circ} \mathrm{C}$ for $30 \mathrm{~s}$, elongation at $72^{\circ} \mathrm{C}$ for $30 \mathrm{~s}$, then 20 cycles of denaturing at $95^{\circ} \mathrm{C}$ for $30 \mathrm{~s}$, annealing at $55^{\circ} \mathrm{C}$ for $30 \mathrm{~s}$, elongation at $72^{\circ} \mathrm{C}$ for $30 \mathrm{~s}$ and a final extension at $72^{\circ} \mathrm{C}$ for $5 \mathrm{~min}$. Then, the PCR product was purified and recovered with MagicPure Size Selection DNA Beads (TransGen Biotech Co., Ltd., Beijing, China), and quantified and normalized with a Qubit ssDNA Assay Kit (Life Technologies, USA). After that, high-throughput sequencing was conducted on the Miseq platform (Illumina, USA) according to the standard procedure by Sangon Biotech (Shanghai) Co., Ltd.

\subsection{Bacterial composition analysis}

Analyses for the high-throughput sequencing data were carried out under the QIIME 2 (Quantitative Insights Into Microbial Ecology, Version 2019.10) framework (Bolyen, Rideout, Dillon, Bokulich, Abnet, Al-Ghalith, ... \& Caporaso, 2019). In brief, ambiguous nucleotides, adapter sequences and primers contained in reads, and short reads with length less than $30 \mathrm{bp}$ were removed with the cutadapt plugin (Martin, 2011). After that, bases in the two ends of reads with quality score lower than 25 were trimmed. And then, reads were truncated to a same length from both ends equivalently. Reads with a length too low to be subjected to truncated operation were discarded. Thereafter, chimeras were filtered, and pair-ended reads were joined, dereplicated, and clustered to operational taxonomic units (OTU) with an identity of 0.97 , by using the Vsearch tool (Rognes, Flouri, Nichols, Quince, \& Mahé, 2016). then, Coverage, Chaol index, Berger-Parker index, Shannon index and Simpson index, were computed with the diversity plugin of QIIME 2. Chao 1 is an index measure the theorical counts of OTUs in a sample, and represent the richness of OTUs; Berger-Parker and Simpson index are dominance or evenness indexes. Berger-Parker index expresses proportional importance of the most abundant species. Whereas, Simpson index represents probability of 2 individuals being conspecifics, and decreases with increase of dominance of predominant species. Shannon index is a synthetic index for judging the richness and evenness of a sample (Magurran, 2004). Finally, OTUs were annotated with the reference GreenGene database 13.8, collapsed at phylum, class, order, family and genus levels, respectively, and visualized with a multilayered pie chart produced by Krona (Ondov, Bergman, \& Phillippy, 2011).

\subsection{Deducing of inferring functions of bacterial community}

Inferring functions of bacterial community were deduced with PICRUSt2 (Phylogenetic Investigation of Communities by Reconstruction of Unobserved States) (Douglas, Maffei, Zaneveld, Yurgel, Brown, Taylor, . . \& \& Langille, 2019). Briefly, OTUs were placed into the reference phylogeny of GreenGene database 13.8 (Barbera, Kozlov, Czech, Morel, Darriba, Flouri, \& Stamatakis, 2018; Czech, Barbera, \& Stamatakis, 2020). Then, hidden-state prediction was run to get $16 \mathrm{~S}$ copy numbers of OTUs to normalize the predicted KEGG Orthology (KO) functions abundances (Louca \& Doebeli, 2017). After that, KEGG pathways abundances were inferred based on predicted $\mathrm{KO}$ functions abundances (Ye \& Doak, 2009). The results were visualized with a multi-layered pie chart produced by Krona (Ondov, Bergman, \& Phillippy, 2011).

The interaction, reaction and relation network of $\mathrm{KO}$ functions involved in nitrogen metabolism was recolored in terms of their relative abundances with KEGG Mapper (Kanehisa \& Sato, 2020), basing on the reference map of 00910 obtained from database of KEGG PATHWAY (https://www.kegg.jp/kegg/pathway.html).

In addition, Enzyme Commission (EC) functions abundances were also predicted and normalized based on $16 \mathrm{~S}$ copy numbers obtained from the hidden-state prediction (Louca \& Doebeli, 2017), to evaluate composition of inferring digestive enzymes (EC 3.1, EC 3.2 and EC 3.4). The results were visualized with a multi-layered pie chart produced by Krona (Ondov, Bergman, \& Phillippy, 2011).

\subsection{Analysis of contributions of bacteria on inferring functions}

Contributions (relative proportions) of bacteria to inferring functions at different levels were analyzed with QIIME 2 (Version 2019.10) (Bolyen, Rideout, Dillon, Bokulich, Abnet, AlGhalith, .. \&\& Caporaso, 2019), respectively.

\subsection{Zootechnical measurement}

Thirty PL were selected randomly and individually weighed to the nearest $0.1 \mathrm{mg}$ with an electric balance (AUX220, Shimadzu, Japan) each week. Weekly increment rate of body 
weight (wiR) and specific growth rate (SGR) were calculated according the following formulates.

$$
\begin{gathered}
\text { wiR }\left(\mathrm{g} \mathrm{week}^{-1}\right)=(\mathrm{fbw}-\mathrm{ibw}) / \text { culture weeks } \\
\operatorname{SGR}\left(\% \mathrm{~d}^{-1}\right)=[(\ln \mathrm{fbw}-\ln \mathrm{ibw}) / \text { culture days }] \times 100 \%
\end{gathered}
$$

Wherein, fbw and ibw represented the final and initial mean body weight of PL, respectively. At $28 \mathrm{~d}$ when the experiment ended, all shrimp in each tank were harvested and counted individually to determine the survival rate (SR).

$$
\text { SR }(\%)=(\text { harvest counts of shrimp/ stocking counts of shrimp }) \times 100 \%
$$

\subsection{Water quality monitoring}

Water temperature, dissolved oxygen and $\mathrm{pH}$ were detected each day by using electric analyzers (YSI-550A, Yellow Springs Instruments Inc., OH, USA). Water sample of each tank was passed thought $0.45-\mu \mathrm{m}$ pore size microfilter (Xinya purification equipment Co., Ltd, Shanghai, China) once a week. Then, the filtrate was used to measure total ammonia nitrogen (TAN), nitrite, nitrate and carbonate alkalinity, and microfilter was used to measure total suspended solid (TSS), according to the standard methods (APHA, 1995). Water sample without filteration was used to determine total nitrogen (TN) weekly (APHA, 1995). Biofloc volume represented with settleable solids (SS) was determined per week with an Imhoff cone, by reading the sediment volume after a 15 min settlement of 1-liter water sample (Avnimelech, 2015).

\subsection{Statistical analysis}

Growth and water quality data in the present study were expressed as mean \pm standard deviation (SD) and statistically analyzed with the SPSS platform for windows (version 22.0, IBM Co., NY, USA). One-way ANOVA was executed as soon as normality distribution of data was proved with Shapiro-Wilk's test. Tukey test or Dunnett's T3 test were adopted for post hoc multiple comparisons of data with equal or unequal variances certified by using Levene's test, respectively, if significant difference was found. Or else, non-parametric Kruskal-Wallis test was conducted, such as TAN, nitrite, biofloc volume (settleable solids) and carbonate alkalinity. Percentage data were submitted to arcsine transformation before statistical analyses. Differences were considered significant at $P<0.05$.

\section{RESULTS}

\subsection{Bacterial composition}

The raw data produced from high-throughput sequencing has been deposited to NCBI Sequence Read Archive database with accession number of SRR12281666. After quality control, a total of 68411 reads with high quality was obtained and clustered to 3712 OTUs, with a Coverage of 0.96, Chao1 index of 13321.2, Berger-Parker index of 0.07, Shannon index of 7.6 and Simpson index of 0.98 . The taxonomy profile was showed in Figure 1, where twenty-five phyla were assigned and dominated by Proteobacteria (45.8\%), Bacteroidetes $\quad(21.1 \%)$, Planctomycetes (13.5\%), Chlamydiae (10.3\%) and Firmicutes (6.8\%). At class level, Alphaproteobacteria (33\%), Planctomycetia (11.8\%), Saprospirae (11.4\%), Chlamydiia $(10.3 \%), \quad$ Gammaproteobacteria $\quad(10.2 \%)$, Flavobacteriia (8\%), Clostridia (3.6\%) and Bacilli (3.2\%), were the dominants (Figure 1). The first 10 predominant orders were Rhizobiales (14.1\%), Rhodobacterales (13.0\%), Saprospirales (11.4\%), Chlamydiales $(10.3 \%)$, Flavobacteriales $(8.0 \%)$, Pirellulales $(7.8 \%)$, Pseudomonadales (4.3\%), Clostridiales (3.6\%), Sphingomonadales (3.1\%) and Lactobacillales (3.1\%) (Figure 1). At other levels, there were nineteen families and eleven genera with proportion of more than $1.0 \%$ (Figure 1).

\subsection{Inferring functions of bacterial community}

Inferring functions (KEGG pathways) profile of bacterial community at three levels (level 13 ) were analyzed. At level 1, Most inferring functions $(81 \%)$ related to metabolism (Figure $2)$. The proportions of other level-1 functions, such as genetic information processing, cellular processes, environmental information 


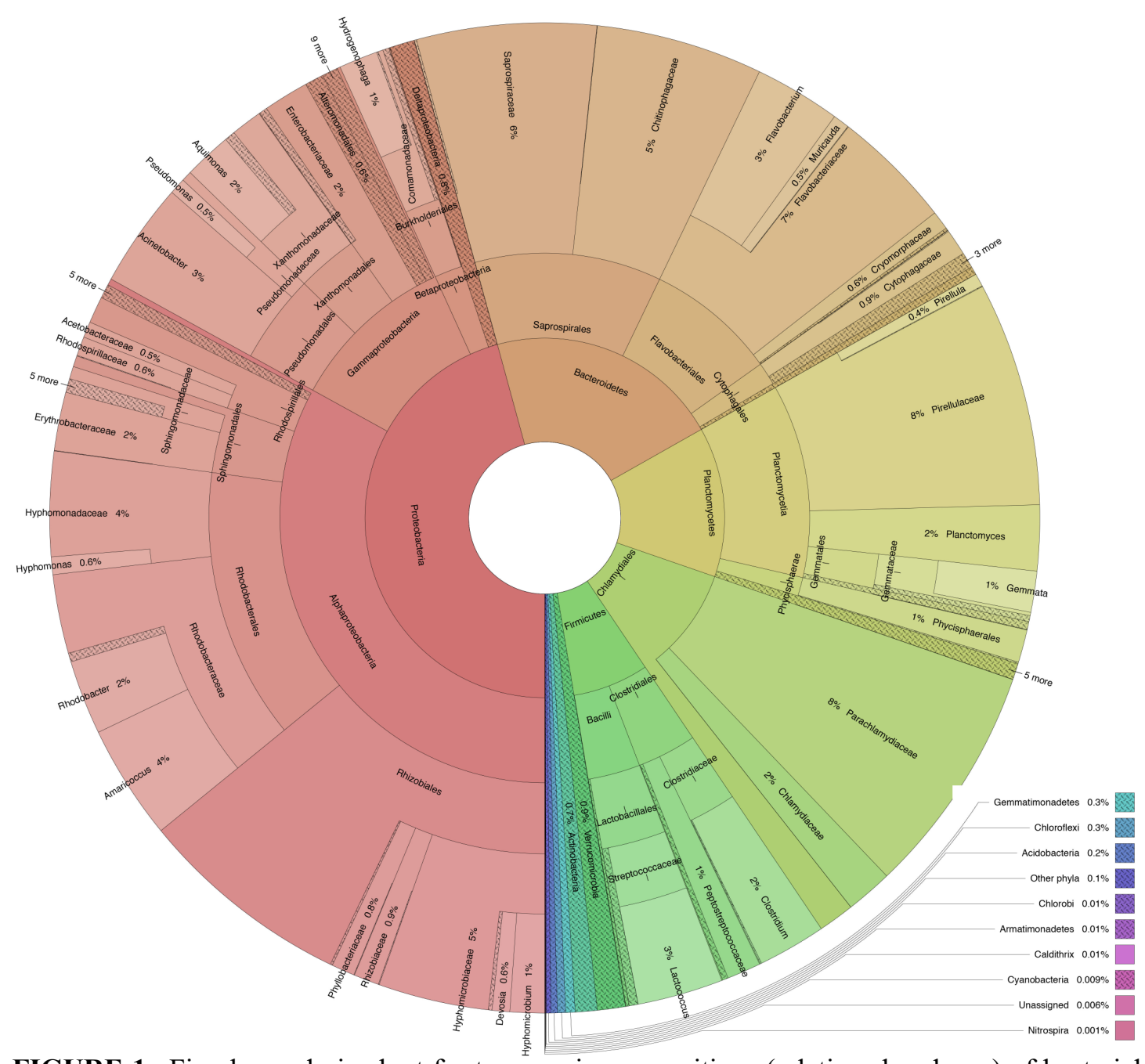

FIGURE 1 Five-layered pie chart for taxonomic compositions (relative abundance) of bacterial community at the end of the experiment ( $28 \mathrm{~d})$ in the biofloc system rearing Litopenaeus vannamei postlarvae with a salinity of $5.0 \%$ at levels of phylum, class, order, family and genera.

processing and organismal systems were $11 \%$, $4 \%, 2 \%$ and $0.4 \%$, respectively (Figure 2 ). The most abundant level-2 functions were those relating to metabolism of nutrients, secondary metabolites and bioactive compounds, such as amino acids (21\%, total of two categories, amino acid and other amino acids), carbohydrate (13\%), lipid (8\%), energy (5\%), cofactors and vitamins (12\%), terpenoids and polyketides $(9 \%)$, xenobiotics $(7 \%)$, and glycan (3\%) (Figure 2). The most abundant Level-3 functions were Valine, leucine and isoleucine biosynthesis (amino acid metabolism), C5-branched dibasic acid metabolism (carbohydrate metabolism), biosynthesis of ansamycins and biosynthesis of vancomysin group antibiotics (metabolism of terpenoids and polyketides), fatty acid biosynthesis and synthesis and degradation of ketone bodies (lipid metabolism), and nitrogen metabolism (energy metabolism) (Figure 2).
Within level-3 KEGG pathway of nitrogen metabolism, the most important $\mathrm{KO}$ functions were referred to conversion of ammonia to glutamate which accounted for $48.5 \%$ (Figure 3 ). The proportion of $\mathrm{KO}$ functions relating to transformations among inorganic nitrogen compounds, such as nitrification, denitrification, and dissimilatory and assimilatory nitrate reduction, was $18.0 \%$ in total, including $1.2 \%$ for nitrite oxidization to nitrate, $7.0 \%$ for nitrate reduction to nitrite and $9.8 \%$ for nitrite reduction to ammonia (Figure 3).

Analysis results basing on predicted EC abundances showed that among enzymes with digestive activities, enzymes acting on ester bonds (EC 3.1), digesting carbohydrates (glycosylases, EC 3.2) and acting on peptide bonds (peptidases, EC 3.4) accounted for 53\%, $15 \%$ and $32 \%$, respectively (Figure S1). And in those three categories, the usual digestive 


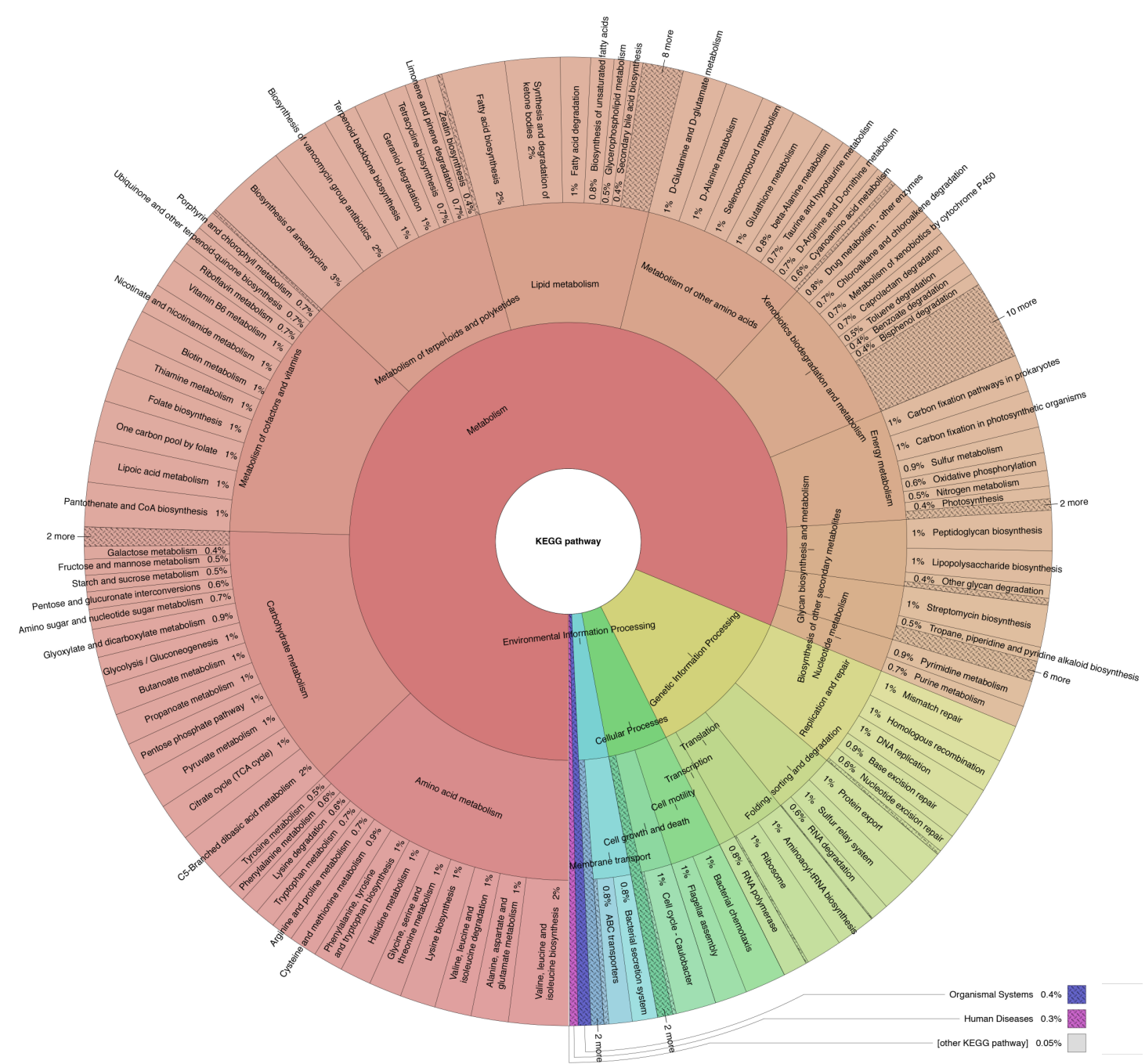

FIGURE 2 Three-layered pie chart for profiles (relative abundance) of level-1, level-2 and level-3 inferring functions of bacterial community at the end of the experiment $(28 \mathrm{~d})$ in the biofloc system rearing Litopenaeus vannamei postlarvae with a salinity of 5.0\%. The inferring functions were represented with KEGG pathways.

enzymes (Fänge \& Grove, 1979; Terra \& Ferreira, 2012), such as triacylglycerol lipase, esterases (carboxylesterases), phosphatases; $\alpha$ amylase, cellulase, chitinase, lysozyme, glucosidases; trypsin and aminopeptidases, were observed (Table 1).

\subsection{Contributions of bacteria on inferring functions}

Four phyla Proteobacteria, Bacteroidetes, Planctomycetes and Firmicutes were found to be very important for the inferring functions (KEGG pathways), and contributed to approximate $89.4 \%$ of total functions (Figure 4). For level-1 functions, Proteobacteria, Planctomycetes and Firmicutes were most important phylum to metabolism, organismal systems and other functions, with contributions of $57.2 \%, 27.8 \%$ and $46.1 \%$, respectively (Figure 4). Proteobacteria played very important roles almost to all level-2 and level3 pathways relating to metabolism (Figures 5). $\mathrm{KO}$ functions contained in level-3 pathway of nitrogen metabolism were mainly contributed to phyla of Proteobacteria, Bacteroidetes, Planctomycetes and Firmicutes (Figure 6).

\subsection{Growth performance of PL and water quality}

At harvest, $91.6 \pm 11.8 \%$ of PL was survived. The mean body weight of PL significantly increased to $120.9 \pm 16.7 \mathrm{mg}$ at $28 \mathrm{~d}(P<0.05$, Figure S2). The concentrations of ammonia, nitrite and nitrate non-significantly oscillated during experiment $(P>0.05$, Figure $\mathrm{S} 3 \mathrm{a})$, with values of $0.04 \pm 0.01,0.2 \pm 0.1$ and $12.9 \pm 2.5 \mathrm{mg}$ $\mathrm{L}^{-1}$ at $28 \mathrm{~d}$, respectively. Whereas, the total nitrogen significantly accumulated to $231.3 \pm 6.0 \mathrm{mg} \mathrm{L}^{-1}$ at $28 \mathrm{~d}(P<0.05$, Figure S3 a). Similarly, biofloc and total suspended solids 


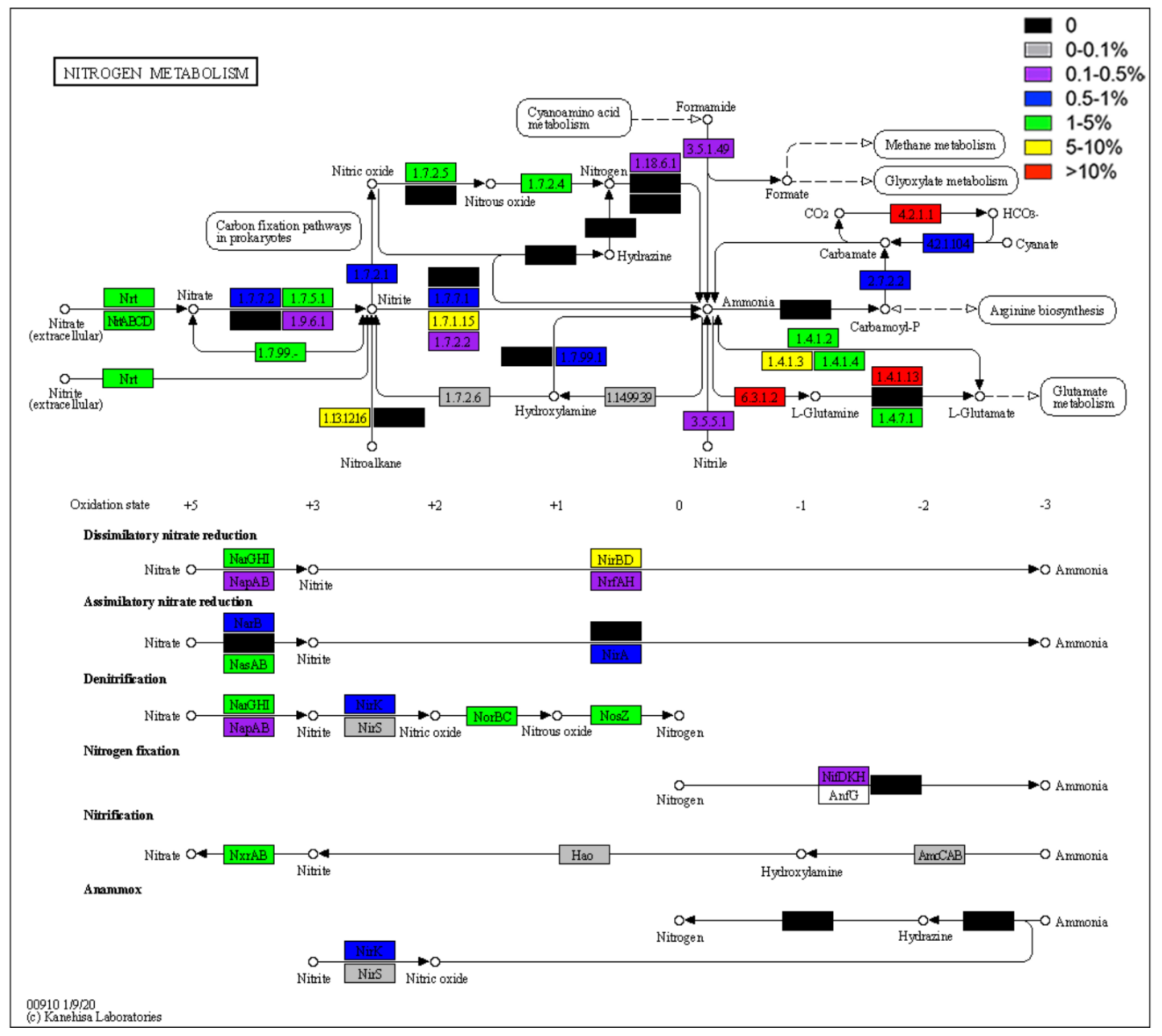

FIGURE 3 Profile of KEGG Orthology (KO) functions involved in the level-3 KEGG pathway of nitrogen metabolism of bacterial community at the end of the experiment $(28 \mathrm{~d})$ in the biofloc system $\mathrm{w}$ rearing Litopenaeus vannamei postlarvae ith a salinity of $5.0 \%$. Recolored in terms of relative abundances of KO functions, basing on the reference map of 00910 obtained from database of KEGG PATHWAY (https://www.kegg.jp/pathway/map00910).

were also significantly accumulated to the levels of $127.0 \pm 63.0 \mathrm{~mL} \mathrm{~L}^{-1}$ and $240.0 \pm 62.0$ $\mathrm{mg} \mathrm{L}^{-1}$ at $28 \mathrm{~d}$, respectively $(P<0.05$, Figure $\mathrm{S} 3 \mathrm{~b}$ ). The value of $\mathrm{pH}$ displayed a significant decreasing trend $(P<0.05$, Figure S3 $\mathrm{c})$, with a final level of $7.4 \pm 0.1$ at $28 \mathrm{~d}$. The rest parameters, such as carbonate alkalinity, water temperature and dissolved oxygen were all stable over the whole experimental period $(P>$ 0.05 , Figure $\mathrm{S} 3 \mathrm{c}$ and $\mathrm{d}$ ), with final values of $268.5 \pm 17.9 \mathrm{mg} \mathrm{L}^{-1} \mathrm{CaCO}_{3}, 29.8 \pm 0.3{ }^{\circ} \mathrm{C}$ and $6.8 \pm 0.1 \mathrm{mg} \mathrm{L}^{-1}$ at $28 \mathrm{~d}$, respectively.

\section{DISCUSSION}

\subsection{Bacterial community properties}

There are two key aspects about diversity of bacterial community, richness and evenness (Magurran, 2004). Chao 1 index measures richness based on rare species, increasing value means increasing of rare species, such as singletons. Several species dominance measurements, such as Berger-Parker index and Simpson index, are used to determine evenness. Berger-Parker index expresses proportional importance of most abundant species, increasing value means reduction in dominance of the most abundant species. Simpson index represents probability of 2 individuals being conspecifics, and increases with decreasing of dominance of the abundant species. Comprehensively, Shannon index indicates richness and evenness simultaneously. In the present study, high values of Chao1 index (13321.2), Shannon index (7.6) and Simpson index (0.98), but low value of BergerParker index (0.07) were observed, suggesting high diversity but low evenness of the bacterial community which was dominated by a few important species. In agreement with this, twenty-five phyla were observed in the present 
TABLE 1 Relative proportions of predicted digestive enzymes in each EC categories of bacterial community at the end of the experiment ( $28 \mathrm{~d}$ ) in the biofloc system rearing Litopenaeus vannamei with a salinity of $5.0 \%$

\begin{tabular}{|c|c|c|c|}
\hline $\begin{array}{l}\text { EC } \\
\text { Categories }\end{array}$ & Enzymes categories & Usual digestive enzymes & $\begin{array}{l}\text { Proportion } \\
\text { s (\%) }\end{array}$ \\
\hline \multirow{9}{*}{$\begin{array}{l}\text { Enzymes } \\
\text { acting on } \\
\text { ester bonds } \\
\text { (EC } 3.1 \text { ) }\end{array}$} & \multirow[t]{2}{*}{ Lipases } & Triacylglycerol lipases (EC 3.1.1.3) & 0.5 \\
\hline & & Esterases (carboxylesterases, EC 3.1.1.1) & 0.3 \\
\hline & \multirow[t]{5}{*}{ Phospholipases } & Phospholipase A2 (EC 3.1.1.4) & 0.2 \\
\hline & & Phospholipase A1 (EC 3.1.1.32) & 0.2 \\
\hline & & Phospholipase B (EC 3.1.1.5) & 2.0 \\
\hline & & Phospholipase C (EC 3.1.4.3) & 0.2 \\
\hline & & Phospholipase D (EC 3.1.4.4) & 0.1 \\
\hline & \multirow[t]{2}{*}{ Phosphatases } & Alkaline phosphatase (EC:3.1.3.1) & 2.5 \\
\hline & & Acid phosphatase (EC 3.1.3.2) & 0.2 \\
\hline \multirow{12}{*}{$\begin{array}{l}\text { Glycosylas } \\
\text { es } \\
\text { (EC 3.2) }\end{array}$} & Amylases & $\alpha$-Amylases (EC 3.2.1.1) & 4.9 \\
\hline & $\beta$-Glucanases & Cellulases (EC 3.2.1.4, EC 3.2.1.91) & 4.0 \\
\hline & Xylanases & Xylanases (EC 3.2.1.8, EC 3.2.1.37) & 1.2 \\
\hline & Pectinases & Pectinases (polygalacturonases, EC 3.2.1.15) & $<0.1$ \\
\hline & Chitinases & Chitinase (EC 3.2.1.14) & 1.0 \\
\hline & Lysozymes & Lysozyme (EC 3.2.1.17) & 0.4 \\
\hline & \multirow[t]{2}{*}{ Glucosidases } & $\alpha$-Glucosidases (EC 3.2.1.20) & 6.0 \\
\hline & & $\beta$-Glucosidase (EC 3.2.1.21) & 7.8 \\
\hline & Trehalases & Trehalase (EC 3.2.1.28) & 0.7 \\
\hline & $\begin{array}{l}\text { Acetylhexosaminidas } \\
\text { es }\end{array}$ & $\beta$-N-acetyl-D-hexosaminidase (EC 3.2.1.52) & 8.2 \\
\hline & $\beta$-Fructosidases & $\beta$-fructosidase (EC 3.2.1.26) & 0.3 \\
\hline & $\alpha$-Galactosidases & $\begin{array}{l}\alpha \text {-D-galactoside galactohydrolase (EC } \\
3.2 .1 .22 \text { ) }\end{array}$ & 2.6 \\
\hline \multirow{4}{*}{$\begin{array}{l}\text { Peptidases } \\
\text { (EC 3.4) }\end{array}$} & Serine proteinases & Trypsin (EC 3.4.21.4) & $<0.1$ \\
\hline & Cysteine proteinase & Cathepsin L (EC 3.4.22.15) & $<0.1$ \\
\hline & \multirow[t]{2}{*}{ Aminopeptidases } & Aminopeptidase N (EC 3.4.11.2) & 2.8 \\
\hline & & Aminopeptidase A (EC 3.4.11.7) & 0.1 \\
\hline
\end{tabular}

study, during which Proteobacteria, Bacteroidetes, Planctomycetes, Chlamydiae and Firmicutes, together represented $97.5 \%$ of the bacteria community. Similarly, in the biofloc systems rearing $L$. vannamei with marine water, 19-22 phyla were found, and Proteobacteria (26-73.88\%), Bacteroidetes (6.57-85\%), Planctomycetes (5.03-42\%) and Firmicutes $(6.48 \%)$ were also the most predominant ones (Huerta-Rabago, MartinezPorchas, Miranda-Baeza, Nieves-Soto, RivasVega, \& Martinez-Cordova, 2019; Mariana, André, Felipe, Walter, Evelyne, Rafael, \& Luciane, 2018; Martínez-Córdova, Francisco, Estefanía, Ortíz-Estrada, Porchas-Cornejo,
Asunción, \& Marcel, 2018; Vargas-Albores, Martínez-Córdova, Gollas-Galván, GaribayValdez, Emerenciano, Lago-Leston, . . . \& Martínez-Porchas, 2019). Species belonging to those phyla, such as classes of Alphaproteobacteria, Planctomycetia, Saprospirae, Gammaproteobacteria and Flavobacteriia, and orders of Rhizobiales, Rhodobacterales, Saprospirales, Flavobacteriales, Pirellulales and Pseudomonadales, have strong adaptation capacity to different environments, especially conditions particularly rich in organic matter and suspended particles in the water column which are usually found in the BFT system, due 


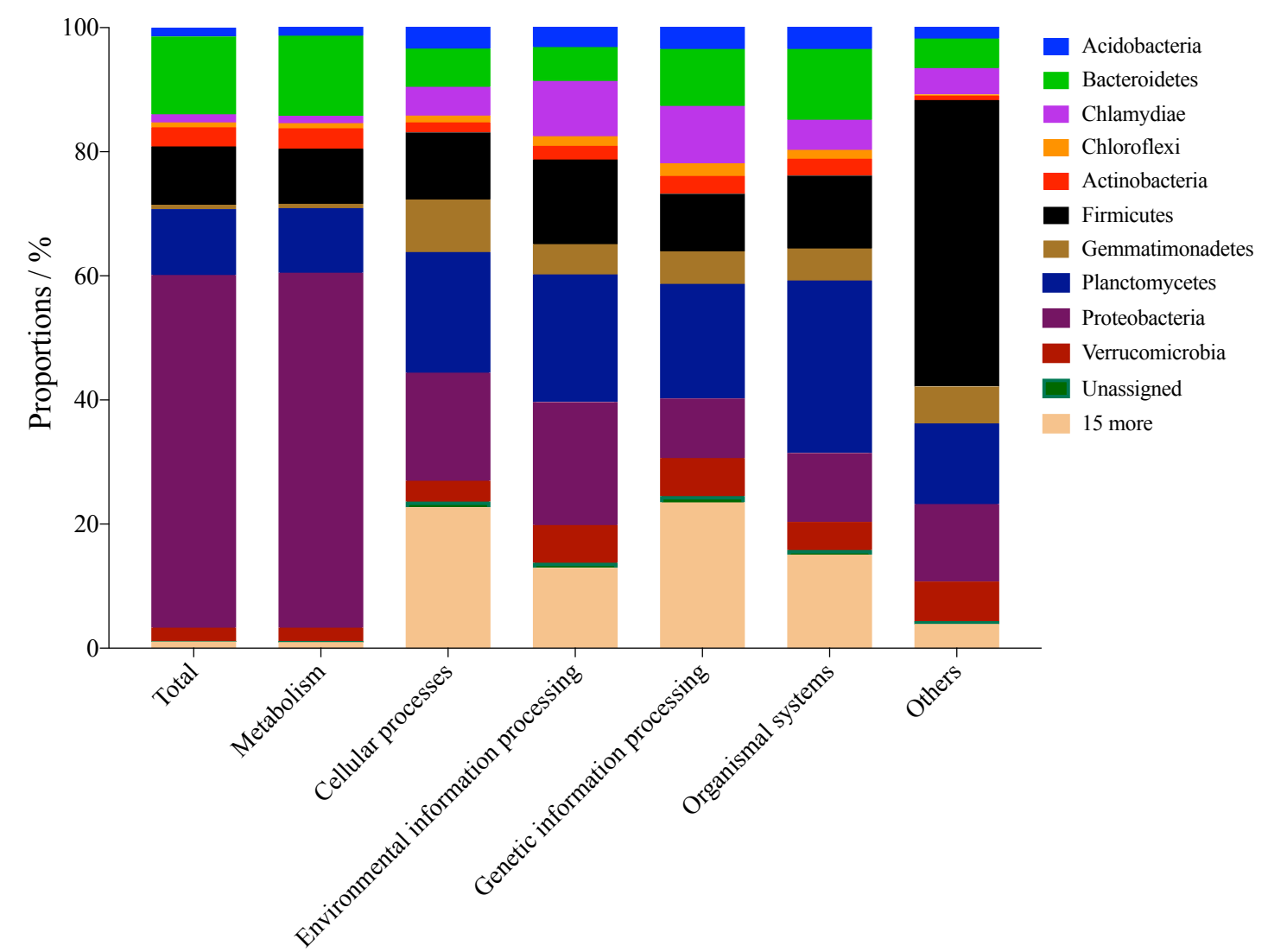

Level-1 KEGG pathways

FIGURE 4 Stacked barchart displaying of contributions (relative proportions) of bacterial community at the end of the experiment ( $28 \mathrm{~d}$ ) in the biofloc system rearing Litopenaeus vannamei postlarvae with a salinity of $5.0 \%$ at phylum level to level-1 inferring functions. The inferring functions were represented with KEGG pathways.

to their abilities to use organic matter and nitrogen compounds for growth and particularity to attach to substrates for requirement of a support to grow on (Cardona, Gueguen, Magre, Lorgeoux, Piquemal, Pierrat, . . . \& Saulnier, 2016; Kersters, Vos, Gillis, Swings, \& Stackebrandt, 2006; Kirchman, 2002; Rank, 2009). Previous studies also revealed that in biofloc systems, although the proportions of the phyla mentioned above were low at initial, they should be predominant at last (Huerta-Rabago, Martinez-Porchas, Miranda-Baeza, Nieves-Soto, Rivas-Vega, \& Martinez-Cordova, 2019; Martínez-Córdova, Francisco, Estefanía, Ortíz-Estrada, PorchasCornejo, Asunción, \& Marcel, 2018; Xu, Xu, Huang, $\mathrm{Hu}, \mathrm{Xu}, \mathrm{Su}, . . . \& \mathrm{Cao}, 2019)$. Whereas, in the freshwater pond rearing fish with biofloc technology, Proteobacteria, Actinobacteria, Fusobateria, Chloroflexi and Saccharibacteria were the most dominant phyla (Liu, Li, Wei, Zhu, Han, Jin, ... \& Xie, 2019), different from the results observed in the present study with a low salinity condition. Whereas, the dominant phyla in the present study were found to be similar with those in the marine biofloc systems rearing L. vannamei (Huerta-Rabago, Martinez-Porchas, Miranda-Baeza, NievesSoto, Rivas-Vega, \& Martinez-Cordova, 2019; Mariana, André, Felipe, Walter, Evelyne, Rafael, \& Luciane, 2018; Martínez-Córdova, Francisco, Estefanía, Ortíz-Estrada, PorchasCornejo, Asunción, \& Marcel, 2018; VargasAlbores, Martínez-Córdova, Gollas-Galván, Garibay-Valdez, Emerenciano, LagoLeston, . . . \& Martínez-Porchas, 2019). It is hypothesized that the similar bacterial composition in the present study with those in seawater biofloc systems might be the result of successful adaptation of bacteria existing in marine-frying water to the low-salinity condition during the desalinating procedure and next operations. However, this adapting process is not clear and should be further studied for a deeper insight.

\subsection{Properties of inferring functions of bacterial community}

Vargas-Albores, Martínez-Córdova, GollasGalván, Garibay-Valdez, Emerenciano, LagoLeston, . . . \& Martínez-Porchas (2019) 


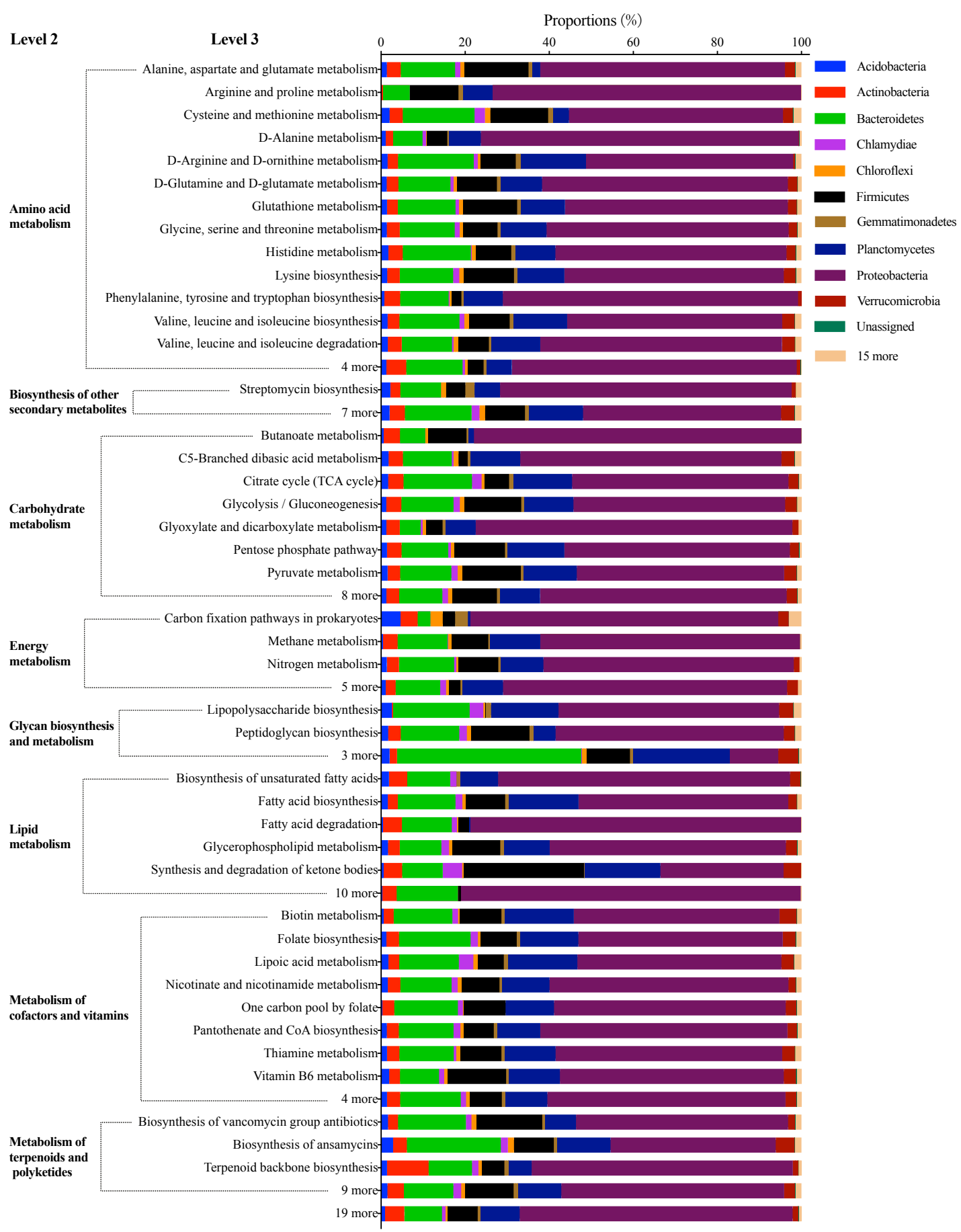

FIGURE 5 Stacked barchart of contributions (relative proportions) of phyla of bacterial community at the end of the experiment ( $28 \mathrm{~d}$ ) in the biofloc system rearing Litopenaeus vannamei postlarvae with a salinity of 5.0\% to level-3 KEGG pathways relating to metabolism (level 1).

documented that most of the predicted level-1 KEGG pathways of bacterial communities in shrimp-culture marine water biofloc systems with amaranth and wheat as biofloc promoters associated with metabolism (50-53\%), genetic information processing (19-21\%), environmental information processing (12$15 \%)$, cellular processes and signaling (4-6\%) and organismal systems (1-2\%), in agreement with the results in the present study. However, compared to this previous study, the proportion of functions relating to metabolism is higher in the current study $(81 \%)$, but those of genetic information processing (11\%) and environmental information processing $(2 \%)$ are lower. Different salinities between the present study and the previous study by VargasAlbores, Martínez-Córdova, Gollas-Galván, Garibay-Valdez, Emerenciano, LagoLeston, . . . \& Martínez-Porchas (2019) might 


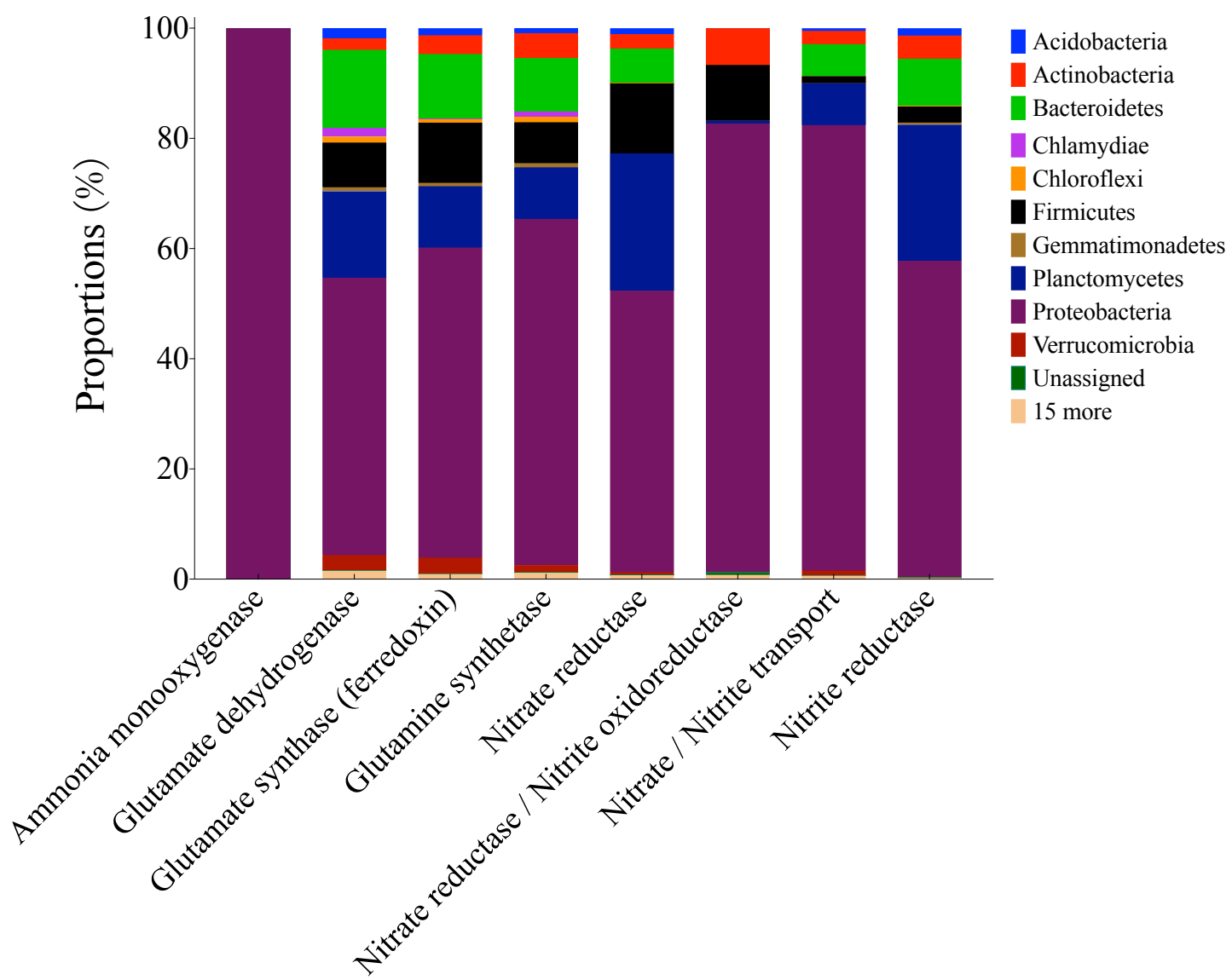

FIGURE 6 Stacked chart for contributions (relative proportions) of bacterial community at the end of the experiment $(28 \mathrm{~d})$ in the biofloc system rearing Litopenaeus vannamei postlarvae with a salinity of $5.0 \%$ at phylum level on the main KEGG Orthology (KO) functions relating to transformations among organic and inorganic nitrogen compounds contained in KEGG pathway of nitrogen metabolism (level 3).

be partially responsible for those differences in inferring functions of bacterial community. Different environmental osmotic pressure under different salinity conditions would make bacteria adjust their physio- and biochemical behaviors. Additionally, other aspects, such as carbon source, $\mathrm{C}: \mathrm{N}$ and age of shrimp, would also affect functions of bacterial community.

At the level 2, the most abundant functions were found to be associated to metabolism, such as metabolism of amino acids, carbohydrates, lipids, nucleotides, vitamins and cofactors, xenobiotics and other metabolites (Vargas-Albores, MartínezCórdova, Gollas-Galván, Garibay-Valdez, Emerenciano, Lago-Leston, . . . \& MartínezPorchas, 2019), also similar with the results in the present study. The high abundance of those metabolic functions suggests that bacteria might be able to take advantage of the suspended substrate and suitable for degradation of organic matter (Vargas-Albores, Martínez-Córdova, Gollas-Galván, GaribayValdez, Emerenciano, Lago-Leston, . . . \&
Martínez-Porchas, 2019), and in turn to improve water quality and formation of bacterial biomass which could be taken as supplementary food for shrimp to improve growth performance.

\subsection{Contribution profile of bacteria to inferring functions}

In the present study, contributions of phyla Proteobacteria, Bacteroidetes, Planctomycetes and Firmicutes to inferring functions were ratable to their proportions in the total bacterial community, respectively. For example, the most abundant phylum Proteobacteria (45.8\%) attributed to $56.8 \%$ of total inferring functions, and played very important roles on almost all function categories. Species belonging to this phylum, such as classes of Alphaproteobacteria and Gammaproteobacteria, orders of Rhizobiales, Rhodobacterales and Enterobacteriales, are widely dispersed in the environment and play important roles in the nutrient cycling and the utilization of organic 
compounds (Berman, 2012; Cardona, Gueguen, Magre, Lorgeoux, Piquemal, Pierrat, ... \& \& Saulnier, 2016). However, the attribution of Chlamydiae to functions was only $1.3 \%$, although it was the fourth predominant phylum (10.3\%). Vargas-Albores, Martínez-Córdova, Gollas-Galván, Garibay-Valdez, Emerenciano, Lago-Leston, . . . \& Martínez-Porchas (2019) found that, compared to the taxonomic profile, the predicted functional profile shows a more effective pattern for representation of sample. This phenomenon should be deserved to note in future studies.

\subsection{Inferring influence of bacterial community on growth performance of $P L$}

Previous studies showed that formation of biofloc was found to be favorable to the growth of PL (Kuhn, Boardman, Lawrence, Marsh, \& Flick, 2009; Xu \& Pan, 2012). Generally, biofloc is considered to be a complementary food to improve growth of shrimp, due to rich in protein, lipid, amino acid and other bioactive compounds (Ju, Ian, Lytha, Warren, Wenhaocedric, \& Floyd, 2008; Kuhn, Boardman, Lawrence, Marsh, \& Flick, 2009; Xu \& Pan, 2012). In the present study, inferring functions of bacterial community relating to metabolism of nutrients were also found, such as biosynthesis of essential and non-essential amino acids, unsaturated fatty acids, and cofactors and vitamins. Moreover, inferring digestive enzymes were also observed, which might be helpful for growth of PL. In biofloc system, bacteria could product exogenous digestive enzymes, increasing the digestibility of foods and improving the growth of shrimp (Panigrahi, Esakkiraj, Jayashree, Saranya, Das, \& Sundaram, 2019; Wang, Pan, Zhang, Xu, Zhao, \& Mei, 2016; Xu, Pan, Sun, \& Huang, 2013). Additionally, inferring functions of bacterial community relating to biosynthesis of immunostimulants (LPS and peptidoglycan) and antibiotics (ansamycins, streptomycin and vancomycins) were observed in the current study, which would be helpful to maintain the high survival rate of PL. Exposure to stimulation of immunostimulants could reinforce the immune system of shrimp (Li \& Xiang, 2013; Panigrahi, Sundaram, Saranya, Swain, Dash, \& Dayal, 2019), and functions of biosynthesis of antibiotics might partially explain why bacterial pathogens do not have the same virulence and are inhibited in biofloc systems (Ekasari, Azhar, Surawidjaja, Nuryati, Schryver, \& Bossier, 2014; Panigrahi, Sundaram, Saranya, Kumar, Dayal,
Saraswathy, ... \& Gopal, 2019). In the current study, proportion of family Vibrionaceae, the most important opportunistic pathogenic bacteria groups for L. vannamei (Gomez-Gil, Tron-Mayén, Roque, Turnbull, Inglis, \& Guerra-Flores, 1998; Kita-Tsukamoto, Oyaizu, Nanba, \& Simidu, 1993), was only $0.003 \%$.

\subsection{Influence of bacterial community on water quality}

The levels of ammonia, nitrite and nitrate at 28 $\mathrm{d}$ were low in this study, indicating that weak nitrification in the system. Actually, Only two families belonging to autotrophic nitrifying bacteria, Nitrospiraceae and Nitrosomonadaceae (Sliekers, Derwort, Gomez, Strous, Kuenen, \& Jetten, 2002), were found in the bacterial community at $28 \mathrm{~d}$ of the present study, with a total proportion of $0.004 \%$. Besides, although some heterotrophic bacteria with nitrification capacity were also found in the bacterial community of the present study, such as genera Acinetobacter, Bacillus, Paracoccus and Pseudomonas (Chen, Luo, Meng, \& Tan, 2019; Liu, Li, Wei, Zhu, Han, Jin, ... \& Xie, 2019), their proportions were also very low. Correspondingly, the proportion of inferring functions of bacterial community relating to inorganic transformation were low (18\% of the level-2 KEGG pathway nitrogen metabolism) in the present study. Conversely, conversion of ammonia to glutamate was the most important $\mathrm{KO}$ functions relating to the level-3 KEGG pathway of nitrogen metabolism in this study. Coincidently, total nitrogen and biofloc significantly accumulated at the end in this study, indicating massive formation of organic nitrogen or bacterial biomass. Heterotrophic bacteria could assimilate inorganic nitrogen to synthesize self-cellular protein, and as a result, massive bacterial biomass produced and biofloc formed (Ebeling, Timmons, \& Bisogni, 2006). Impressively, the level of biofloc volume increased to $127.0 \pm 63.0 \mathrm{~mL} \mathrm{~L}^{-1}$ at the end of the experiment (28 d) in the present study, far higher than the acceptable value for shrimp (Avnimelech, 2015; $\mathrm{Xu}$ \& Pan, 2012), meaning that removal treatment should be executed in next studies, but the effect of this treatment on bacterial community should be investigated as well.

It should be noted that in the present study, only the bacterial community at the end of experiment ( $28 \mathrm{~d}$ ) was determined, leading to that only qualitative relationship between bacterial community and water parameters determined at the same time could be 
speculated, and that no tighter associations or quantitative correlations could be obtained. Thereby, interestingly and meaningfully, more treatments would be built up to get deeper insight of effects of bacterial community on growth performance and water quality in next studies.

\section{CONCLUSION}

The bacterial community at $28 \mathrm{~d}$ in the biofloc system rearing $L$. vannamei PL with a low salinity of $5.0 \%$ was highly diverse, and dominated by Proteobacteria, Bacteroidetes, Planctomycetes and Firmicutes. Those dominant species contributed to most of inferring functions of the bacterial community. Among the functions relating to nitrogen metabolism, $48.5 \%$ were involved in the conversion of ammonia to glutamate, but the proportion of those involved in transformation among ammonia, nitrite and nitrate was $18.0 \%$ in total, inferring higher protein-synthesis but lower inorganic nitrogen compoundstransformation capacities of the bacterial community, which were consistent with the practical levels of nitrogen compounds in water body at the same time ( $28 \mathrm{~d})$, suggesting important roles of bacterial community in biofloc system.

\section{ACKNOWLEDGEMENTS}

This work is financially supported by the development funds of the Chinese central government to guide local science and technology (2017CT5013), the Sci-Tech program of Hunan province (2016NK2132), the scientific research program of the Education Department of Hunan province (18B394), the open projects of Key Laboratory of Health Aquaculture and Product Processing in Dongting Lake Area of Hunan Province (2018KJ001) and Changde Research Center for Agricultural Biomacromolecule (2020AB08).

\section{CONFLICT OF INTEREST}

The authors have no conflict of interest.

\section{AUTHOR CONTRIBUTIONS}

Hai-Hong Huang: designed study and drafted the paper. Ting Luo: performed laboratory analysis. Yan-Ju Lei: analyzed the data. WeiQi Kuang: performed metagenomics analysis. Wan-Sheng Zou: performed laboratory analysis. Pin-Hong Yang: involved in English edition.

\section{DATA AVAILABILITY STATEMENT}

Data are available if required.

\section{ORCID}

Hai-Hong Huang https://orcid.org/ 0000-00031570-2163

\section{REFERENCES}

APHA. (1995). Standard methods for the examination of water and wastewater. Washington, DC: American public health association.

Avnimelech, Y. (2015). Biofloc technology: a practical hand book, 3rd ed. Baton Rouge, Louisiana, EUA: The world aquaculture society.

Avnimelech, Y. (1999). Carbon/nitrogen ratio as a control element in aquaculture systems. Aquaculture, 176(3), 227-235.

Barbera, P., Kozlov, A. M., Czech, L., Morel, B., Darriba, D., Flouri, T., \& Stamatakis, A. (2018). EPA-ng: Massively parallel evolutionary placement of genetic sequences. Systematic Biology, 68(2), 365369. doi:10.1093/sysbio/syy054

Berman, J. J. (2012). The Alpha Proteobacteria. Boston: Academic Press.

Bolyen, E., Rideout, J. R., Dillon, M. R., Bokulich, N. A., Abnet, C. C., Al-Ghalith, G. A., . . . Caporaso, J. G. (2019). Reproducible, interactive, scalable and extensible microbiome data science using QIIME 2. Nature Biotechnology, 37(8), 852-857. doi:10.1038/s41587-019-0209-9

Cardona, E., Gueguen, Y., Magre, K., Lorgeoux, B., Piquemal, D., Pierrat, F., . . . Saulnier, D. (2016). Bacterial community characterization of water and intestine of the shrimp Litopenaeus stylirostris in a biofloc system. Bmc Microbiology, 16. doi:10.1186/s12866-016-0770-z

Chen, X., Luo, G.Z., Meng, H., \& Tan, F. Y. (2019). Effect of the particle size on the ammonia removal rate and the bacterial community composition of bioflocs. Aquacultural Engineering, 86(102001), 1-8.

Czech, L., Barbera, P., \& Stamatakis, A. (2020). Genesis and Gappa: processing, analyzing and visualizing phylogenetic (placement) data. Bioinformatics, 36(10), 3263-3265. doi:10.1093/bioinformatics/btaa070

Douglas, G. M., Maffei, V. J., Zaneveld, J., Yurgel, S. N., Brown, J. R., Taylor, C. M., . . . Langille, M. G. I. (2019). PICRUSt2: An improved and extensible approach for metagenome inference. 
bioRxiv.

Ebeling, J. M., Timmons, M. B., \& Bisogni, J. J. (2006). Engineering analysis of the stoichiometry of photoautotrophic, autotrophic, and heterotrophic removal of ammonia-nitrogen in aquaculture systems. Aquaculture, 257(1-4), 346-358. doi:http://dx.doi.org/10.1016/j.aquaculture .2006.03.019

Ekasari, J., Azhar, M. H., Surawidjaja, E. H., Nuryati, S., Schryver, P. D., \& Bossier, P. (2014). Immune response and disease resistance of shrimp fed biofloc grown on different carbon sources. Fish \& Shellfish Immunology, 41(2), 332-339. doi:10.1016/j.fsi.2014.09.004

Fänge, R., \& Grove, D. (1979). Digestion. In W. S. Hoar, D. J. Randall, \& J. R. Brett (Eds.), Fish physiology (Vol. 8, pp. 161-260). New York: Academic Press.

FAO. (2020). The state of world fisheries and aquaculture - Sustainability in action. Rome: https://doi.org/10.4060/ca9229en

Gaona, C. A. P., Almeida, M. S. d., Viau, V., Poersch, L. H., \& Wasielesky, W. Jr. (2017). Effect of different total suspended solids levels on a Litopenaeus vannamei (Boone, 1931) BFT culture system during biofloc formation. Aquaculture Research, 48(3), 1070-1079. doi:10.1111/are.12949

Gomez-Gil, B., Tron-Mayén, L., Roque, A., Turnbull, J. F., Inglis, V., \& Guerra-Flores, A. L. (1998). Species of Vibrio isolated from hepatopancreas, haemolymph and digestive tract of a population of healthy juvenile Penaeus vannamei. Aquaculture, 163(1-2), 0-9.

Hargreaves, J. (2013). Biofloc production systems for aquaculture. United States, Department of Agriculture, National Institute of Food and Agriculture: Southern Regional Aquaculture Center.

Huang, H. H. (2020). Novel biofloc technology (bft) for ammonia assimilation and reuse in aquaculture in situ. In Q. Lu \& $\mathrm{M}$. Serajuddin (Eds.), Emerging Technologies and Research for Eco-friendly Aquaculture (pp. 3-22). London: IntechOpen.

Huerta-Rabago, J. A., Martinez-Porchas, M., Miranda-Baeza, A., Nieves-Soto, M., Rivas-Vega, M. E., \& Martinez-Cordova, L. R. (2019). Addition of commercial probiotic in a biofloc shrimp farm of Litopenaeus vannamei during the nursery phase: Effect on bacterial diversity using massive sequencing 16S rRNA. Aquaculture, 502, 391-399. doi:10.1016/j.aquaculture.2018.12.055
Ju, Z. Y., Ian, F., Lytha, C., Warren, D., Wenhaocedric, K., \& Floyd, D. H. (2008). Determination of microbial community structures of shrimp floc cultures by biomarkers and analysis of floc amino acid profiles. Aquaculture Research, 39(2), 118133.

Kanehisa, M., \& Sato, Y. (2020). KEGG Mapper for inferring cellular functions from protein sequences. Protein science, 29(1), 28-35. doi:doi:10.1002/pro.3711

Kersters, K., Vos, P. D., Gillis, M., Swings, J., \& Stackebrandt, E. (2006). Introduction to the Proteobacteria. In M. Dworkin, S. Falkow, E. Rosenberg, K. H. Schleifer, \& E. Stackebrandt (Eds.), The Prokaryotes. New York: Springer.

Khanjani, M. H., Sajjadi, M. M., Alizadeh, M., \& Sourinejad, I. (2017). Nursery performance of Pacific white shrimp (Litopenaeus vannamei Boone, 1931) cultivated in a biofloc system: the effect of adding different carbon sources. Aquaculture Research, 48(4), 1491-1501. doi:10.1111/are.12985

Kirchman, D. L. (2002). The ecology of Cytophaga-Flavobacteria in aquatic environments. FEMS Microbiology Ecology, 39(2), 91-100.

Kita-Tsukamoto, K., Oyaizu, H., Nanba, K., \& Simidu, U. (1993). Phylogenetic relationships of marine bacteria, mainly members of the family Vibrionaceae, determined on the basis of $16 \mathrm{~S}$ rRNA sequences. International Journal of Systematic \& Evolutionary Microbiology, 43, 8-19.

Kuhn, D. D., Boardman, G. D., Lawrence, A. L., Marsh, L., \& Flick, G. J., Jr. (2009). Microbial floc meal as a replacement ingredient for fish meal and soybean protein in shrimp feed. Aquaculture, 296(12), 51-57. doi:10.1016/j.aquaculture.2009.07.025

Kumar, S., Anand, P. S. S., De, D., Deo, A. D., Ghoshal, T. K., Sundaray, J. K., ... Lalitha, N. (2017). Effects of biofloc under different carbon sources and protein levels on water quality, growth performance and immune responses in black tiger shrimp Penaeus monodon (Fabricius, 1978). Aquaculture Research, 48(3), 1168-1182. doi:10.1111/are.12958

Lara, G., Krummenauer, D., Abreu, P. C., Poersch, L. H., \& Wasielesky, W. Jr. (2017). The use of different aerators on Litopenaeus vannamei biofloc culture system: effects on water quality, shrimp 
growth and biofloc composition. Aquaculture International, 25(1), 147-162. doi:10.1007/s10499-016-0019-8

Li, F., \& Xiang, J. (2013). Recent advances in researches on the innate immunity of shrimp in China. Developmental \& Comparative Immunology, 39(1), 11-26.

Li, J., Liu, G., Li, C., Deng, Y., Abubakar, T. M., Lan, L., . . . Liu, D. (2018). Effects of different solid carbon sources on water quality, biofloc quality and gut microbiota of Nile tilapia (Oreochromis niloticus) larvae. Aquaculture, 495, 919-931.

Liu, H., Li, H., Wei, H., Zhu, X., Han, D., Jin, J., . . . Xie, S. (2019). Biofloc formation improves water quality and fish yield in a freshwater pond aquaculture system. Aquaculture, 506, 256-269. doi:10.1016/j.aquaculture.2019.03.031

Louca, S., \& Doebeli, M. (2017). Efficient comparative phylogenetics on large trees. Bioinformatics, 34(6), 1053-1055. doi:10.1093/bioinformatics/btx701

Luo, G., Liu, Z., Shan, L., \& Tan, H. (2019). Using poly-beta-hydroxybutyric as an additional carbohydrate for biofloc in a shrimp Litopenaeus vannamei bioflocs nursery system with brackish water. Aquaculture, 506, 181-187. doi:10.1016/j.aquaculture.2019.03.021

Magurran, A. E. (2004). Measuring biological diversity. Oxford: Blackwell Publishing.

Mariana, P., André, G., Felipe, V., Walter, S., Evelyne, B., Rafael, R., \& Luciane, P. (2018). Exploring the impact of the biofloc rearing system and an oral WSSV challenge on the intestinal bacteriome of Litopenaeus vannamei. Microorganisms, 6(83), 1-16.

Martin, M. (2011). Cutadapt removes adapter sequences from high-throughput sequencing reads. Embnet Journal, 17(1), $10-12$.

Martínez-Córdova, L. R., Francisco, V. A., Estefanía, G. V., Ortíz-Estrada, á. M., Porchas-Cornejo, M. A., Asunción, L. L., \& Marcel, M. P. (2018). Amaranth and wheat grains tested as nucleation sites of microbial communities to produce bioflocs used for shrimp culture. Aquaculture, 497, 503-509.

Mishra, J. K., Samocha, T. M., Patnaik, S., Speed, M., Gandy, R. L., \& Ali, A.-M. (2008). Performance of an intensive nursery system for the Pacific white shrimp, Litopenaeus vannamei, under limited discharge condition. Aquacultural Engineering, 38(1), 2-15.
Ondov, B., Bergman, N., \& Phillippy, A. (2011). Interactive metagenomic visualization in a Web browser. BMC Bioinformatics, 12(1), 385.

Panigrahi, A., Esakkiraj, P., Jayashree, S., Saranya, C., Das, R. R., \& Sundaram, M. (2019). Colonization of enzymatic bacterial flora in biofloc grown shrimp Penaeus vannamei and evaluation of their beneficial effect. Aquaculture International, 27(6), 1835-1846. doi:10.1007/s10499-01900434-X

Panigrahi, A., Sundaram, M., Saranya, C., Kumar, S. R., Dayal, S. J., Saraswathy, R., . . . Gopal, C. (2019). Influence of differential protein levels of feed on production performance and immune response of pacific white leg shrimp in a biofloc-based system. Aquaculture, 503, 118-127. doi:10.1016/j.aquaculture.2018.12.036

Panigrahi, A., Sundaram, M., Saranya, C., Swain, S., Dash, R. R., \& Dayal, J. S. (2019). Carbohydrate sources deferentially influence growth performances, microbial dynamics and immunomodulation in Pacific white shrimp (Litopenaeus vannamei) under biofloc system. Fish \& Shellfish Immunology, 86(3), 1207-1216.

Piedrahita, R. H. (2003). Reducing the potential environmental impact of tank aquaculture effluents through intensification and recirculation. Aquaculture, 226(1), 35-44.

Ray, A. J., Leffler, J. W., \& Browdy, C. L. (2019). The effects of a conventional feed versus a fish-free feed and biofloc management on the nutritional and human sensory characteristics of shrimp (Litopenaeus vannamei). Aquaculture International, 27(1), 261-277. doi:10.1007/s10499-018-0321-8

Ray, A. J., \& Lotz, J. M. (2017). Comparing salinities of 10,20 , and $30 \%$ in intensive, commercial-scale biofloc shrimp (Litopenaeus vannamei) production systems. Aquaculture, 476, 29-36.

Rezende, P. C., Schleder, D. D., Silva, H. V. d., Henriques, F. M., Lorenzo, M. A. d., Seiffert, W. Q., . . . Vieira, F. d. N. (2018). Prenursery of the Pacific white shrimp in a biofloc system using different artificial substrates. Aquacultural Engineering, 82, 25-30.

Rognes, T., Flouri, T., Nichols, B., Quince, C., \& Mahé, F. (2016). VSEARCH: a versatile open source tool for metagenomics. PeerJ, 4, e2584. doi:10.7717/peerj.2584 
Roy, L. A., Davis, D. A., Saoud, I. P., Boyd, C. A., Pine, H. J., \& Boyd, C. E. (2010). Shrimp culture in inland low salinity waters. Reviews in Aquaculture, 2(4), 191-208.

Samocha, T. M. (2010). Use of intensive and super-intensive nursery systems (V. AldaySanz Ed.). Nottingham: Nottingham University Press.

Schryver, P. D., Crab, R., Defoirdt, T., Boon, N., \& Verstraete, W. (2008). The basics of bioflocs technology: the added value for aquaculture. Aquaculture, 277(3), 125-137.

Schveitzer, R., Lorenzo, M. A. D., Felipe, D. N. V., Pereira, S. A., Mourino, J. L. P., Seiffert, W. Q., \& Andreatta, E. R. (2017). Nursery of young Litopenaeus vannamei postlarvae reared in biofloc- and microalgaebased systems. Aquacultural Engineering, 78, 140-145.

Sliekers, A. O., Derwort, N., Gomez, J. L. C., Strous, M., Kuenen, J. G., \& Jetten, M. S. M. (2002). Completely autotrophic nitrogen removal over nitrite in one single reactor. Water Research, 36(10), 24752482.

Terra, W. R., \& Ferreira, C. (2012). Biochemistry and molecular biology of digestion. In L. I. Gilbert (Ed.), Insect Molecular Biology and Biochemistry (pp. 365-418). San Diego: Academic Press.

Van Wyk, P., Davishodgkins, M., Laramore, R., Main, K. L., Mountain, J., \& Scarpa, J. (1999). Farming marine shrimp in recirculating freshwater systems. Tallahassee: Florida department of agriculture and consumer services.

Vargas-Albores, F., Martínez-Córdova, L. R., Gollas-Galván, T., Garibay-Valdez, E., Emerenciano, M. G. C., Lago-Leston, A., . . . Martínez-Porchas, M. (2019). Inferring the functional properties of bacterial communities in shrimp-culture bioflocs produced with amaranth and wheat seeds as fouler promoters. Aquaculture, 500, 107-117.

Wang, C., Pan, L., Zhang, K., Xu, W., Zhao, D., \& Mei, L. (2016). Effects of different carbon sources addition on nutrition composition and extracellular enzymes activity of bioflocs, and digestive enzymes activity and growth performance of Litopenaeus vannamei in zero-exchange culture tanks. Aquaculture Research, 47(10), 3307-3318. doi:10.1111/are.12784

Xu, W., Xu, Y., Huang, X., Hu, X., Xu, Y., Su, H., . . Cao, Y. (2019). Addition of algicidal bacterium CZBC1 and molasses to inhibit cyanobacteria and improve microbial communities, water quality and shrimp performance in culture systems. Aquaculture, 502, 303-311.

Xu, W.J., \& Pan, L.Q. (2012). Effects of bioflocs on growth performance, digestive enzyme activity and body composition of juvenile Litopenaeus vannamei in zerowater exchange tanks manipulating $\mathrm{C} / \mathrm{N}$ ratio in feed. Aquaculture, 356-357, 147152.

doi:http://dx.doi.org/10.1016/j.aquaculture .2012.05.022

Xu, W. J., Pan, L. Q., Sun, X. H., \& Huang, J. (2013). Effects of bioflocs on water quality, and survival, growth and digestive enzyme activities of Litopenaeus vannamei (Boone) in zero-water exchange culture tanks. Aquaculture Research, 44(7), 1093-1102. doi:10.1111/j.1365-2109.2012.03115.x

Ye, Y., \& Doak, T. G. (2009). A Parsimony approach to biological pathway reconstruction/inference for genomes and metagenomes. PLOS Computational Biology, 5(8), e1000465. doi:10.1371/journal.pcbi.1000465 